\title{
Influence of degree of specific allergic sensitivity on severity of rhinitis and asthma in Chinese allergic patients
}

Jing Li $i^{1}$, Ying Huang ${ }^{2}$, Xiaoping Lin ${ }^{3}$, Deyu Zhao ${ }^{4}$, Guolin Tan ${ }^{5}$, Jinzhun $\mathrm{Wu}^{6}$, Changqing Zhao ${ }^{7}$, Jing Zhao ${ }^{8}$, Michael D Spangfort ${ }^{9}$, Nanshan Zhong $^{1 *}$ and for

China Alliance of Research on Respiratory Allergic Disease (CARRAD)

\begin{abstract}
Background: The association between sensitizations and severity of allergic diseases is controversial.

Objective: This study was to investigate the association between severity of asthma and rhinitis and degree of specific allergic sensitization in allergic patients in China.

Method: A cross-sectional survey was performed in 6304 patients with asthma and/or rhinitis from 4 regions of China. Patients completed a standardized questionnaire documenting their respiratory and allergic symptoms, their impact on sleep, daily activities, school and work. They also underwent skin prick tests with 13 common aeroallergens. Among the recruited subjects, 2268 provided blood samples for serum measurement of specific lgE (slgE) against 16 common aeroallergens.
\end{abstract}

Results: Significantly higher percentage of patients with moderate-severe intermittent rhinitis were sensitized to outdoor allergens while percentage of patients sensitized to indoor allergens was increased with increasing severity of asthma. Moderate-severe intermittent rhinitis was associated with the skin wheal size and the level of slgE to Artemisia vulgaris and Ambrosia artemisifolia $(p<0.001)$. Moderate-severe asthma was associated with increasing wheal size and slgE response to Dermatophagoides (D.) pteronyssinus and D. farinae $(p<0.001)$. Moderate-severe rhinitis and asthma were also associated with increase in number of positive skin prick test and slgE.

Conclusions: Artemisia vulgaris and Ambrosia artemisifolia sensitizations are associated with the severity of intermittent rhinitis and D. pteronyssinus and D. farinae sensitizations are associated with increasing severity of asthma in China. Increase in number of allergens the patients are sensitized to may also increase the severity of rhinitis and asthma.

Keywords: sensitization, aeroallergens, disease severity, allergic rhinitis, asthma, association.

\section{Background}

The prevalence of asthma and allergic rhinitis symptoms varies considerably across the world [1,2]. In China, the prevalence of allergic rhinoconjunctivitis symptoms varies from 8.7 to $24.1 \%$ documented by self-reported telephone interviews conducted between 2004 and 2005 in 11 cities [3]. The prevalence of respiratory allergy is increasing in China $[3,4]$ and an international comparative study found

\footnotetext{
* Correspondence: nanshan@vip.163.com

'State Key Laboratory of Respiratory Disease, The First Affiliated Hospital,

Guangzhou Medical College, Guangzhou, Guangdong, China

Full list of author information is available at the end of the article
}

that in the city of Guangzhou, the prevalence of asthma symptoms among children aged 13-14 years increased from $3.4 \%$ in 1995 to $4.8 \%$ in 2001 [4] and to $6.1 \%$ in 2009 (unpublished data).

Atopic sensitization is a risk factor for the development of upper and lower respiratory symptoms [5,6]. Exposure to allergens the patients are sensitized to may exacerbate symptoms of rhinitis and asthma by promoting airway inflammation, airflow limitation, and airway hyperreponsiveness (AHR). Sensitization to indoor allergens correlates well with indoor allergen exposure in pre-school and school-age children $[7,8]$. Furthermore, exposure and

\section{Biomed Central}


sensitivity follows a dose-dependent relationship [9]. Evidence supporting this relationship is particularly strong for house dust mite (HDM) sensitization [9]. Allergic rhinitis can also be caused by pollens from grasses and trees which are the most important sources of outdoor sensitizing allergens $[10,11]$. We have previously performed an epidemiological study of the prevalence of sensitization in patients with asthma and/or rhinitis in mainland China [12]. For indoor and outdoor allergens, we found that house dust mite sensitization was consistently associated with asthma whereas Artemisia vulgaris and Ambrosia artemisifolia pollen sensitizaions were associated with the development of rhinitis [12].

Both rhinitis and asthma are diseases of variable severity. Many studies have shown that the degree of allergic sensitivity as reflected by elevated serum allergen-specific IgE levels or allergen skin wheal size is related to asthma severity $[13,14]$, however, other studies $[15,16]$ did not find this relationship.

Thus, the influence of the degree of allergic sensitivity on the disease severity of allergic asthma and rhinitis remains uncertain. The aim of this study was to investigate the relationship between size of skin test or level of serum specific IgE and the severity of asthma and rhinitis in Chinese patients based on data from a recently conducted nation-wide multicentre epidemiology study.

\section{Methods}

\section{Study population and definitions}

The study was a cross-sectional epidemiologic survey, conducted from February 2006 to March 2007 in 17 cities with 24 participating centers from northern, eastern, south western and southern coastal regions of China. The study covered mid-temperate, warm-temperate, subtropical and tropical zones of China. Patients aged 5 to 65 years attending outpatient clinics at 24 centers, and diagnosed as rhinitis and/or asthma, were invited to participate in this survey. By evaluating their history, questionnaire and relevant tests, rhinitis was defined as having symptoms of sneezing, or a running, itchy or blocked nose when the patient did not have a cold or flu. Asthma was defined by a history of recurrent dyspnea, wheezing or cough episodes, positive airway reversibility testing $\left(\mathrm{FEV}_{1}\right.$ increasing $\geq 12 \%$ and $200 \mathrm{ml}$ after inhalation of $400 \mathrm{mg}$ of salbuta$\mathrm{mol})$ or positive airway responsiveness testing $\left(\mathrm{FEV}_{1}\right.$ decreasing $\geq 20 \%$ when $\leq 7.8 \mu \mathrm{mol}$ of cumulative dose of histamine is administered). The study was approved by the Ethics Review Board of each study center and all patients gave written consent before the study.

\section{Questionnaire}

The standardized questionnaire was administered by the trained physicians or research nurses face-to-face with questions regarding demographic characteristics, family history of allergic diseases, symptoms of rhinitis, wheezing or coughing, eczema and burning or itchy eyes, smoking habits, environmental exposure factors, animal pet ownership and dietary habits. Questions about impact of allergic symptoms on daily activities, work or school, night-time sleep, and use of medications for controlling the symptoms were also documented.

\section{Assessment of severity of rhinitis and asthma}

According to the Allergic Rhinitis and its Impact on Asthma guidelines [17], rhinitis was classified as "mild" and "moderate/severe" depending on the severity of symptoms and their impact on sleep, daily activities, school and work evaluated by the questionnaire. Severity of asthma was classified according to the 2006 version of Global Initiative for Asthma guidelines [18].

\section{Skin prick test (SPT)}

The sensitivity to thirteen common aeroallergens was tested including Dermatophagoides (D.) pteronyssinus, D. farinae and Blomia tropicalis, dog, cat, Periplaneta americana, Blatella germanica, Artemisia vulgaris, Ambrosia artemisifolia, mixed grass and tree pollen, mould mix I and IV. Allergen extracts and control solutions were obtained from ALK (Horsholm, Denmark). Histamine $(10 \mathrm{mg} / \mathrm{ml})$ and diluent were used as positive and negative controls. SPT was performed on the volar side of the forearm. The wheal reaction after 15 minutes was measured as the mean of the longest diameter and the length of the perpendicular line through its middle. A positive skin reaction was defined as a wheal size $3 \mathrm{~mm}$ greater than the negative control. The result was also expressed as skin index (SI = mean size of allergen wheal/mean size of histamine wheal). Atopy was defined as the presence of at least one positive skin reaction to any allergen tested.

We originally recruited 6411 questionnaires and 6393 skin test reports. Among the 6411 questionnaires, 107 were invalid for lacking proper diagnosis, incompletely answering the questionnaire or missing skin test report. Of the 6393 skin test reports, 89 were rejected for missing questionnaire data, wrong codings, or missing the histamine and normal saline readings. Hence, we restricted our final valid data with 6304 patients.

\section{Serum specific IgE Analysis}

Among the 24 centers, 14 of them obtained serum samples from their subjects for sIgE analysis. With the written consents, peripheral blood was obtained from patients in the above centers only after completing the questionnaires and skin prick tests. Finally, 2268 out of the 6304 patients ( 806 with rhinitis alone, 773 with asthma alone and 689 with both rhinitis and asthma) from four regions provided blood for measurement of 
serum allergen-specific IgE (sIgE). Ten $\mathrm{ml}$ of blood from each subject was coagulated at room temperature, centrifuged, stored at $-20^{\circ} \mathrm{C}$. The sIgE against $D$. pteronyssinus, D. farinae, cat, dog, Periplaneta americana, Blatella germanica, Penicillium, Cladosporium, Fusarium, sycamore, willow, cottonwood, elm, grass pollen, Artemisia vulgaris, Ambrosia artemisifolia was measured with the ADVIA Centaur ${ }^{\circledR}$ immunoassay system (Bayer Healthcare LLC, Tarrytown New York, USA) [19]. The analysis for sIgE was defined to be positive if the measurement was $\geq 0.35 \mathrm{kU} / \mathrm{L}$.

\section{Quality control}

Standardized protocol, questionnaire, allergen skin prick testing set, and operating procedures were used by all the centers. All questionnaire interviewers and performers of skin prick testing were trained before the study. Results of questionnaire and skin prick tests were sent every month to Guangzhou, where the data were input and analyzed. Quality control reports were then prepared for each center. Each completed questionnaire and skin test report was verified by the center supervisor and the results were double-checked by the principal investigator and fed back to each center. All questionnaires and skin test data were coded and input into a programmed database by two persons independently. The entered data were checked for out-of-range values and logic mistakes.

\section{Statistical analysis}

For all analyses $\mathrm{p}<0.05$ was regarded as statistically significant. Prevalences of sensitization to various groups of allergens are presented. The differences of the sensitization rate between different severities of rhinitis and asthma were determined by chi-square tests. Skin prick test mean wheal diameter were used as raw data. The relationship between quantitative mean skin wheal diameter and severity of rhinitis or asthma was analyzed using logistic regression. Fitted predicted probability curves of moderate-severe rhinitis and asthma according to the wheal size of skin sensitizations were plotted using the results from the logistic regression. For the quantitative evaluations, the OR are presented for different skin prick test mean wheal diameters expressing the increased risk of severity of rhinitis and asthma associated with increasing skin wheal size. For associations between sIgE concentrations and different severities of rhinitis and asthma, we calculated the prevalence of rhinitis and asthma severities with different sIgE levels against $D$. pteronyssinus, D. farinae, Artemisia vulgaris and Ambrosia artemisifolia SIgE and the statistical significance of the differences were determined by using chi-square tests. All data were categorized and analyzed using the Statistical Package for the Social Sciences (SPSS Inc. Chicago, IL, USA) for Windows Release 13.0 and Microcal
Origin 6.0 (Microcal Software Inc., Northampton, MA, USA).

\section{Results}

Of the 6304 patients, 967 subjects had mild intermittent rhinitis, 452 had moderate-severe intermittent rhinitis, 1729 had mild persistent rhinitis and 1154 had moderatesevere persistent rhinitis. Asthma was under control in 741 patients while 441 patients had intermittent asthma (step 1), 735 with mild persistent (step 2), 948 with moderate persistent (step 3) and 915 with severe persistent asthma (step 4). Patients with moderate-severe intermittent rhinitis had significantly higher prevalence of sensitization to dogs, Artemisia vulgaris, Ambrosia artemisifolia, mixed grass pollen and mixed tree pollen $(\mathrm{p}<0.001)$ by skin prick tests. They also showed significantly greater percentage of multiple sensitizations $(\mathrm{p}<0.05)$. Prevalence of sensitization to $D$. pteronyssinus, $D$. farinae, blomia tropicalis, dog and cat was increased with increasing of disease severity in patients with asthma. Furthermore, with increasing severity of asthma, there is higher proportion of patients with multiple sensitizations (Table 1).

Serum specific IgE against 16 common aeroallergens was measured in 2268 patients in whom 175 were classified as mild intermittent rhinitis, 281 as moderate-severe intermittent rhinitis, 596 as mild persistent rhinitis and 339 as moderate-severe persistent rhinitis. For asthma patients, 405 were at mild intermittent stage, 313 at mild persistent, 335 at moderate persistent and 628 at severe persistent stage. D. pteronyssinus and D. farinae were found to be the most prevalent allergens followed by Artemisia vulgaris and Ambrosia artemisifolia with SIgE measurements in patients with rhinitis and asthma. Significantly higher percentage of patients with moderatesevere intermittent rhinitis was sensitized to Artemisia vulgaris $(\mathrm{p}<0.001)$, Ambrosia artemisifolia $(\mathrm{p}<0.001)$, willow ( $\mathrm{p}<0.01)$, elm $(\mathrm{p}<0.05)$ and grass pollen $(\mathrm{p}<$ 0.05 ). Elevated levels of sIgE against $D$. pteronyssinus and $D$. farinae in patients with asthma were associated with increasing the severity $(\mathrm{p}<0.001)$. Multiple sensitizations was significantly associated with increasing in level of asthma severity $(\mathrm{p}<0.001)$ (Table 2$)$.

\section{Allergen skin test sizes and severity of rhinitis and asthma}

Using allergen skin prick test wheal size as a continuous variable, the risk of having moderate-severe rhinitis in our patients was at around $40 \%-42.5 \%$ when they were not sensitized to Artemisia vulgaris (Figure 1A) or Ambrosia artemisifolia (Figure 1B), or any tested allergen (Figure 1C). But the risk increased significantly with increasing skin wheal size to Artemisia vulgaris (OR 1.12, 95\% CI 1.07-1.14, p < 0.001) and Ambrosia artemisifolia (OR 1.19, 95\% CI 1.13-1.41, $\mathrm{p}<0.001$ ) corresponding to 
Table 1 Prevalence (\%) of allergen skin sensitizations in patients with rhinitis and asthma of different severity

\begin{tabular}{|c|c|c|c|c|c|c|c|c|c|c|c|c|}
\hline & & & Rhinitis & & & & & & Asthma & & & \\
\hline & $\begin{array}{c}\text { MI } \\
(\mathrm{n}=967)\end{array}$ & $\begin{array}{c}\text { MSI } \\
(n=452)\end{array}$ & $\begin{array}{c}\text { MP } \\
(n=1729)\end{array}$ & $\begin{array}{c}\text { MSP } \\
(n=1154)\end{array}$ & $\chi^{2}$ & $p$ & $\begin{array}{c}\text { MI } \\
(n=441)\end{array}$ & $\begin{array}{c}\text { MIP } \\
(n=735)\end{array}$ & $\begin{array}{c}\text { MOP } \\
(n=948)\end{array}$ & $\begin{array}{c}\text { SP } \\
(n=915)\end{array}$ & $x^{2}$ & $p$ \\
\hline D. pteronyssinus & 61.1 & 59.7 & 61.8 & 60.9 & 7.0 & 0.092 & 51.7 & 58.5 & 62.0 & 64.5 & 34.6 & 0.000 \\
\hline D. farinae & 62.1 & 60.6 & 64.3 & 63.1 & 3.16 & 0.371 & 52.6 & 60.2 & 63.7 & 65.6 & 36.5 & 0.000 \\
\hline Blomia tropicalis & 43.3 & 43.3 & 44.4 & 44.9 & 0.6 & 0.901 & 32.3 & 39.0 & 44.4 & 48.4 & 56.7 & 0.000 \\
\hline Dog & 15.9 & 20.1 & 14.0 & 16.5 & 13.8 & 0.003 & 12.4 & 13.2 & 14.3 & 18.0 & 17.2 & 0.001 \\
\hline Cat & 9.8 & 13.1 & 10.5 & 10.1 & 5.03 & 0.17 & 8.7 & 11.7 & 12.9 & 13.6 & 11.0 & 0.012 \\
\hline American cockroach & 15.3 & 16.7 & 16.9 & 17.2 & 0.88 & 0.83 & 15.8 & 17.4 & 16.6 & 19.4 & 5.8 & 0.12 \\
\hline Blatella germanica & 10.7 & 13.7 & 12.8 & 13.0 & 2.53 & 0.47 & 9.9 & 10.6 & 13.3 & 13.2 & 8.2 & 0.042 \\
\hline Artemisia vulgaris & 16.5 & 30.5 & 8.0 & 13.1 & 202.4 & 0.000 & 9.8 & 7.7 & 9.6 & 8.8 & 2.3 & 0.52 \\
\hline Ambrosia artemisifolia & 10.9 & 20.1 & 3.9 & 6.9 & 167.7 & 0.000 & 5.2 & 4.7 & 5.2 & 4.1 & 2.5 & 0.483 \\
\hline${ }^{1}$ Mixed grass pollen & 3.1 & 4.8 & 2.0 & 1.5 & 21.0 & 0.000 & 2.4 & 2.1 & 2.7 & 2.3 & 0.7 & 0.872 \\
\hline${ }^{2}$ Mixed tree pollen & 4.6 & 8.2 & 2.2 & 3.8 & 45.5 & 0.000 & 4.9 & 2.1 & 3.2 & 3.9 & 7.7 & 0.053 \\
\hline${ }^{3}$ Mixed mould I & 6.9 & 6.3 & 7.8 & 6.2 & 7.6 & 0.07 & 6.2 & 7.7 & 8.1 & 8.2 & 2.9 & 0.409 \\
\hline${ }^{4}$ Mixed mould IV & 5.4 & 5.0 & 5.9 & 4.1 & 6.0 & 0.13 & 4.8 & 4.2 & 6.0 & 5.5 & 2.9 & 0.404 \\
\hline$\geq 2$ sensitizations & 72.6 & 74.3 & 68.5 & 69.5 & 9.548 & 0.023 & 59.4 & 65.3 & 70.3 & 71.1 & 34.24 & 0.000 \\
\hline
\end{tabular}

${ }^{1}$ Mixed grass pollen: Dactylis glomerata, Festuca pratensis, Lolium perenne, Phleum pretense and Poa pratensis; ${ }^{2}$ Mixed tree pollen: Ulmus americana, Platanus acerifolia, Salix caprea and Populus deltoids; ${ }^{3}$ Mixed mould I: Alternaria alternata, Cladosporium herbarum, Fusarium sp and Chaetomium globosum; ${ }^{4}$ Mixed mould IV: Penicillium (P.) brevicompactum, P. expansum, P. notatum and P. roqueforthi. MI: mild intermittent; MSI: moderate-severe intermittent; MP: mild persistent; MSP: moderate-severe persistent; MIP: mild persistent; MOP: moderate persistent; SP: severe persistent.

OR of 4.29 and 4.85 at $10 \mathrm{~mm}$ wheal size, and 11.52 and 23.71 at $20 \mathrm{~mm}$, respectively (Figure 1A-1B). Similarly, when patients were not sensitized to $D$. pteronyssinus (Figure 1D) and D. farinae (Figure 1E), or to the tested allergens (Figure 1F), the probability of having moderatesevere asthma was at around 66\%, but the risk increased for 1.21 -fold per $\mathrm{mm}$ increase in skin wheal size to $D$. pteronyssinus and D. farinae (95\% CI 1.09-1.46 and 1.101.47 respectively, $\mathrm{p}<0.001$ ), corresponding to an OR of 1.84 and 1.74 at $10 \mathrm{~mm}$ wheal size, and 2.76 and 2.63 at $20 \mathrm{~mm}$, respectively (Figure 1D-1E). In addition, moderate-severe rhinitis and asthma were also associated with increasing number of skin sensitized allergens (Figure 1C, F).

Table 2 Prevalence (\%) of serum specific IgE positivity to tested allergens in patients with rhinitis and asthma of different severity

\begin{tabular}{|c|c|c|c|c|c|c|c|c|c|c|c|c|}
\hline & & & Rhinitis & & & & & & Asthma & & & \\
\hline & $\begin{array}{c}\text { MII } \\
(n=175)\end{array}$ & $\begin{array}{c}\text { MSI } \\
(n=281)\end{array}$ & $\begin{array}{c}\text { MIP } \\
(n=596)\end{array}$ & $\begin{array}{c}\text { MSP } \\
(n=339)\end{array}$ & $\chi^{2}$ & $p$ & $\begin{array}{c}\text { MII } \\
(n=405)\end{array}$ & $\begin{array}{c}\text { MIP } \\
(n=313)\end{array}$ & $\begin{array}{c}\text { MOP } \\
(n=335)\end{array}$ & $\begin{array}{c}\text { SEP } \\
(\mathrm{n}=628)\end{array}$ & $\chi^{2}$ & $p$ \\
\hline D. pteronyssinus & 44.3 & 45.2 & 50.2 & 47.0 & 2.96 & 0.401 & 22.7 & 52.4 & 59.4 & 79.1 & 332.6 & 0.000 \\
\hline D. farinae & 43.8 & 46.0 & 49.1 & 44.7 & 2.56 & 0.463 & 21.0 & 49.2 & 58.5 & 77.2 & 320.2 & 0.000 \\
\hline Cat & 10.2 & 7.8 & 9.1 & 10.1 & 1.17 & 0.765 & 7.3 & 9.8 & 9.5 & 10.5 & 1.90 & 0.594 \\
\hline Dog & 5.4 & 3.9 & 4.2 & 5.2 & 1.03 & 0.792 & 2.1 & 4.4 & 3.0 & 5.1 & 4.86 & 0.182 \\
\hline American cockroach & 0 & 1.6 & 1.3 & 0.6 & 3.13 & 0.372 & 2.3 & 1.1 & 1.1 & 1.8 & 1.46 & 0.712 \\
\hline Blatella germanica & 0 & 3.5 & 2.2 & 2.3 & 5.75 & 0.125 & 1.6 & 2.9 & 4.0 & 2.3 & 3.68 & 0.302 \\
\hline Penicillium & 2.1 & 0.9 & 1.3 & 0.3 & 3.40 & 0.337 & 0 & 0.6 & 1.2 & 1.3 & 4.38 & 0.209 \\
\hline Cladosporium & 0 & 0 & 0.2 & 0 & 1.26 & 0.741 & 0 & 0 & 0 & 0.3 & 1.62 & 0.795 \\
\hline Fusarium & 29.1 & 28.2 & 23.9 & 24.2 & 2.29 & 0.515 & 17.9 & 22.6 & 25.7 & 22.7 & 2.534 & 0.470 \\
\hline Sycamore & 5.1 & 5.6 & 2.1 & 3.3 & 7.57 & 0.060 & 2.3 & 2.2 & 1.8 & 2.7 & 0.741 & 0.867 \\
\hline Willow & 3.8 & 6.8 & 2.0 & 4.0 & 11.9 & 0.008 & 1.7 & 1.6 & 2.9 & 2.9 & 1.773 & 0.642 \\
\hline Cottonwood & 5.0 & 6.8 & 2.7 & 4.5 & 7.83 & 0.050 & 2.8 & 2.1 & 3.6 & 3.4 & 0.998 & 0.805 \\
\hline Elm & 6.8 & 9.1 & 4.1 & 4.5 & 9.63 & 0.024 & 2.2 & 2.1 & 3.1 & 4.0 & 2.837 & 0.416 \\
\hline Grass pollen & 4.3 & 4.4 & 1.3 & 2.8 & 8.87 & 0.030 & 1.1 & 0 & 1.9 & 2.1 & 4.55 & 0.212 \\
\hline Artemisia vulgaris & 19.5 & 27.1 & 6.1 & 6.7 & 93.2 & 0.000 & 5.4 & 4.0 & 4.8 & 5.4 & .747 & 0.870 \\
\hline Ambrosia artemisifolia & 14.9 & 29.2 & 0.7 & 0.9 & 98.7 & 0.000 & 0 & 0 & 0.7 & 1.2 & 4.651 & 0.184 \\
\hline$\geq 2$ sensitizations & 16.3 & 21.8 & 19.9 & 21.8 & 7.30 & 0.063 & 15.8 & 18.8 & 21.7 & 26.6 & 39.1 & 0.000 \\
\hline
\end{tabular}

MII: Mild intermittent; MSI: Moderate-severe intermittent; MIP: Mild persistent; MSP: Moderate-severe persistent; MOP: Moderate persistent; SEP: Severe persistent 


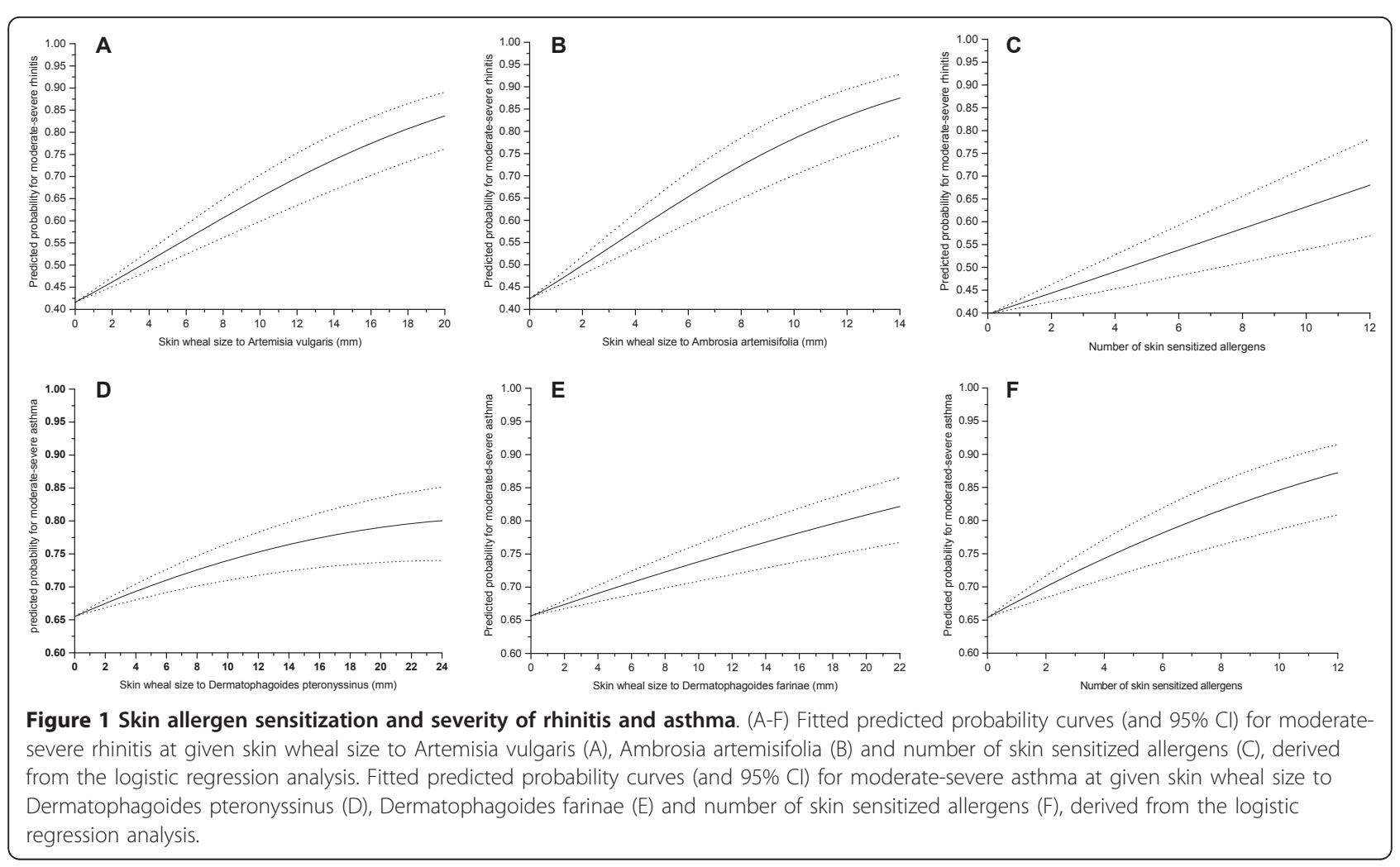

Allergen slgE levels and severity of asthma and rhinitis Among patients with rhinitis, we found that significantly higher percentage of patients with moderate-severe intermittent rhinitis had higher level of sIgE to Artemisia vulgaris and Ambrosia artemisifolia ( $\mathrm{p}<0.001$ ) but not to $D$. pteronyssinus and D. farinae (Figure 2). For asthma patients, sIgE levels against D. pteronyssinus and D. farinae, but not Artemisia vulgaris and Ambrosia artemisifolia, were significantly associated with increasing of asthma severity $(\mathrm{p}<0.001)$ (Figure 3$)$.

\section{Discussion}

In this nation-wide multicentre epidemiologic study of more than 6300 asthmatic and rhinitis patients with varying disease severity in China, we found D. pteronyssinus and $D$. farinae sensitizations were significantly associated with severity of asthma while Artemisia vulgaris and Ambrosia artemisifolia sensitizations were related to severity of rhinitis. Furthermore, multiple allergen sensitization was also associated with severity of rhinitis and asthma as determined by either skin prick test or sIgE measurements.

In this paper, our data show that severity of asthma was significantly correlated with skin index of reactivity to D. pteronyssinus, D. farinae and Blomia tropicalis. Furthermore, we also found that elevated levels of sIgE to $D$. pteronyssinus and $D$. farinae correlate significantly with increasing severity of asthma. Our findings support the concept that sensitization against indoor allergens may affect asthma severity $[13,20]$. Allergens induce sensitizations in persons who are in high risk and repetitive exposure to the allergens may lead to allergic inflammatory reactions in the airway mucosa [21]. Airway inflammation may be variably associated with changes in airway hyperresponsiveness, airflow limitation, respiratory symptoms, and disease chronicity [22]. Our finding that patients who had HDM sensitization were more likely to have more severe asthma, compared to those without sensitization, is consistent with many other studies in children or adults [23]. Platts-Mills et al. [24] reported that load of house dust mites is associated with the onset of respiratory allergic conditions, especially bronchial asthma, and that there exists a threshold of HDM exposure to induce symptoms of asthma. Even exposure to low levels of mite allergens $(0.02-2.0 \mu \mathrm{g} / \mathrm{g}$ dust) was found to be a significant risk factor for sensitization [25]. A few studies found several species of HDM in indoor environment in China [26,27] and relatively high levels of HDM group 1 allergens (> $10 \mu \mathrm{g} / \mathrm{g}$ dust) has been detected in a very high proportion of dust samples from southern China [28].

Not surprisingly, we demonstrated quantitative association between the size of skin test and the specific IgE levels to pollens especially Artemisia vulgaris and 


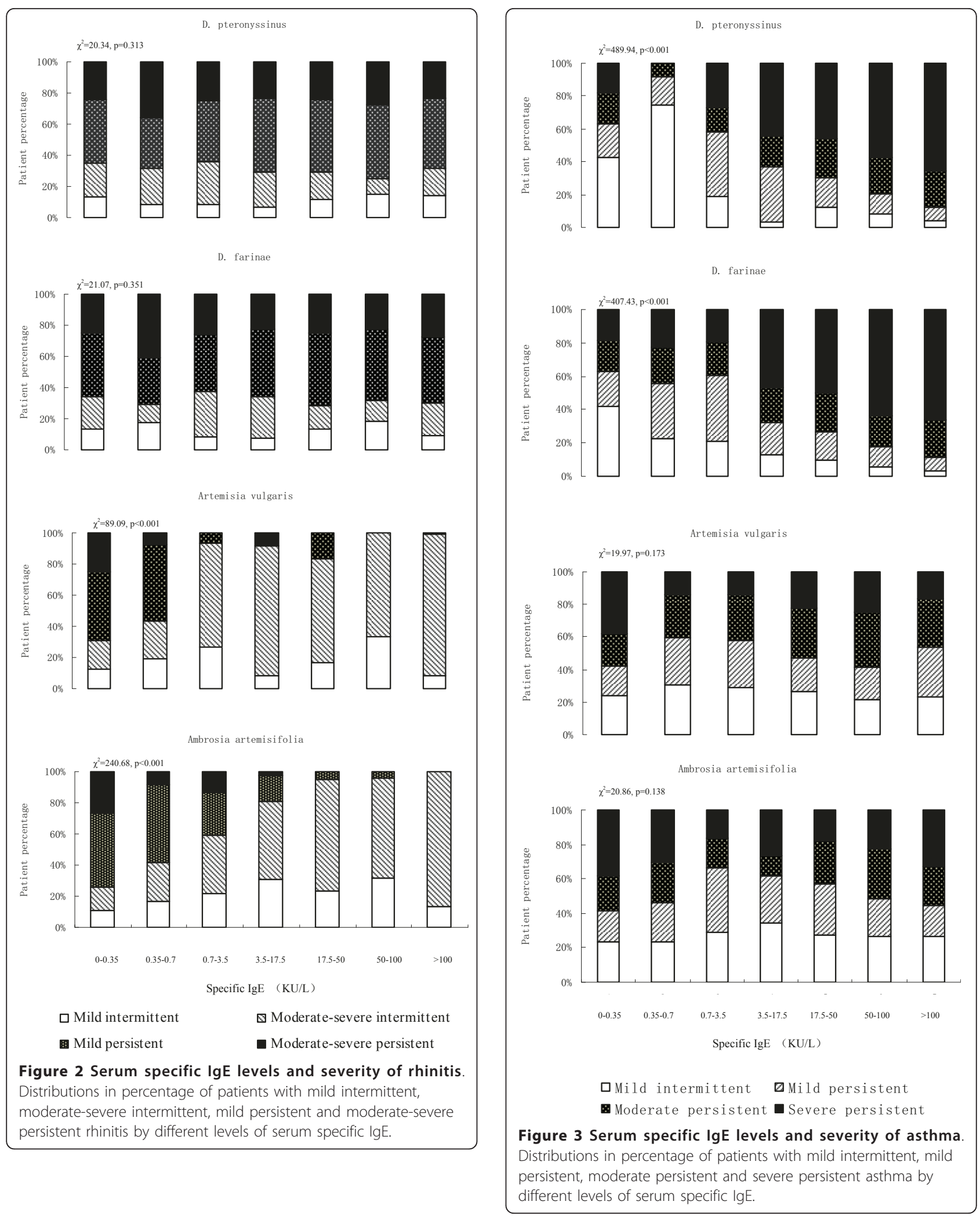


Ambrosia artemisifolia and moderate-severe intermittent rhinitis. Although we did not analyze the data by stratification of the patients with regions and seasons in this paper, we predict that these patients are mainly from the northern parts of China undergoing clinical sampling during the season from July to September [12]. One recently published study [11] demonstrated that sIgE levels to birch- and grass-pollen at baseline as well as during the pollen season were associated with seasonal symptom severity of rhinitis and use of rescue medications. In contrast, adult patients with seasonal allergic rhinitis have been investigated by several studies in this respect. Some investigators found a positive association between sIgE levels and clinical symptoms [29,30], although symptoms were also dependent on other factors, such as the ease of histamine release by basophils. Other studies did not find strong associations or reported inconsistent findings [31,32]. This inconsistency may be explained by differences in allergens, age or other characteristics of the patient populations studied. At least this seems to be the reason for a marked variability in the outcome of a variety of studies investigating the capacity to predict symptomatic allergy from sIgE levels in children [33]. We therefore assume that some of the above-mentioned differences among studies in respiratory allergies may be explained by the varying parameters of the allergens studied, the age of the patients and the measurements of clinical disease severity.

Surprisingly, we failed to find the relationship between HDM skin test size and specific IgE levels and severity of any type of rhinitis, especially persistent rhinitis, however, our finding supports the facts that outdoor allergens affect rhinitis significantly $[13,20]$. Many studies have shown that pollen such as Artemisia vulgaris and Ambrosia artemisifolia is a larger allergen compared with HDMs and is mainly deposited in the upper airway where it induces local inflammatory or pathological changes, whereas enzymatic activity of pyroglyphid mites seems to be important in the pathogenicity of lower airway and systemic inflammations $[34,35]$. We have extended this observation by demonstrating the same associations for Chinese weed grass pollens Artemisia vulgaris and Ambrosia artemisifolia within the group of patients defined as atopic using standard definitions [17]. These findings also indicate that IgE-mediated sensitization is not dichotomous in its relation to the expression, severity and temporal pattern of upper and lower respiratory allergic diseases.

In this study, we also found by both skin test and sIgE measurements that patients with sensitizations to multiple allergens were significantly more likely to have more severe rhinitis and asthma. Our results are in agreement with the study by Simpson et al. [36]. They investigated a group of adults with asthma showing that sensitization to dust mite, cat, dog, and mixed grasses as well as multiple sensitizations were all independently associated with asthma. The data of another study [13] suggested that the development of specific IgE response to multiple indoor allergens is an important factor in the persistence of bronchial obstruction in children with asthma.

In summary, the results of the current study emphasize the importance of sensitization to indoor allergens in asthma severity and to outdoor allergens in severity of rhinitis. Sensitization to more than one allergenic source also significantly increases the possibility of developing moderate-severe rhinitis and asthma.

\section{Acknowledgements}

Members of China Alliance of Research on Respiratory Allergic Disease (CARRAD) include Jing Li, Chunqing Zhang, Hongyu Wang, Dehui Chen, Baoging Sun, Ying Huang, Xiaoping Lin, Deyu Zhao, Guolin Tan, Jinzhun Wu, Changqing Zhao, Jing Zhao, Ling Cao, Guangfa Wang, Changchun Sun, Dongdong Zhu, Xiaoqin Zhou, Nan Su, Jiangtao Lin, Xuefen Wang, Jianying Zhou, Wen Li, Huahao Shen, Yijiang Huang, Shi Chen, Xiaofan Liu, Chuangli Hao, Hong Han, Shaohua Chen, Wei Tang, Huanying Wan, Xiaoyan Dong, Yixiao Bao, Luo Zhang, Dehou Xue, Michael D. Spangfort, Nanshan Zhong. All authors contributed equally to this study. The authors thank Professor Gary Wing-kin Wong, department of paediatrics, The Chinese University of Hong Kong and Birgitte Gjesing, ALK-Abello A/S for help in editing the manuscript; Ms. Mei Jiang, Guangzhou Institute of Respiratory Disease, Guangzhou Medical College, China, for assistance in statistical considerations. This study was supported by ALK-Abello A/S (FC409(10441)-ALK).

\section{Author details}

'State Key Laboratory of Respiratory Disease, The First Affiliated Hospital, Guangzhou Medical College, Guangzhou, Guangdong, China. 'The Children's Hospital, Chongqing University of Medical Sciences, Chongqing, China. ${ }^{3}$ The General Hospital of Shenyang Military Command, Shenyang, Liaoning, China. ${ }^{4}$ Nanjing Children's Hospital, Nanjing, Jiangsu, China. ${ }^{5}$ The Third Hospital of Xiangya Medical University, Changsha, Hunan, China. ${ }^{6}$ The First Hospital of Xiamen, Xiamen, Fujian, China. ${ }^{7} T$ The Second Hospital of Shanxi Medical University, Taiyuan, Shanxi, China. ${ }^{8}$ Capital Institute of Pediatrics, Beijing, China. ${ }^{9}$ ALK-Abello A/S, Asia Pacific Region, Hongkong, China.

\section{Authors' contributions}

$J L$ mainly designed the study, performed the survey, collected the data, performed the statistical analysis and the drafted the manuscript. YH participated in designing the study, performed the survey, collected the data and drafted the manuscript. XL participated in designing the study, performed the survey, and collected the data. DZ participated in designing the study, performed the survey and collected the data. GT performed the survey, collected the data. JW participated in designing the study, performed the survey and collected the data, $\mathrm{HZ}$ performed the survey and collected the data. JZ participated in designing the study, performed the survey and collected the data. MS designed the study, performed the statistical analysis and the drafted the manuscript. NZ mainly designed the study, performed the statistical analysis and the drafted the manuscript. All members of China Alliance of Research on Respiratory Allergic Disease participated in discussion the protocol of the study, perform the survey and collected the data. All authors read and approved the final manuscript.

\section{Competing interests}

The authors declare that they have no competing interests.

Received: 28 March 2011 Accepted: 15 July 2011

Published: 15 July 2011

\section{References}

1. Weinmayr G, Genuneit J, Nagel G, Bjorksten B, van Hage M, Priftanji A, Cooper P, Rijkjarv MA, von Mutius E, Tsanakas J, Forastiere F, Doekes G, 
Garrido JB, Suarez-Varela M M, Braback L, Strachan DP: International variations in associations of allergic markers and diseases in children: ISAAC Phase Two. Allergy 2010, 65:766-775.

2. Piau JP, Massot C, Moreau D, Aït-Khaled N, Bouayad Z, Mohammad Y, Khaldi F, Bah-Sow O, Camara L, Koffi NB, M'boussa J, El Sony A, Moussa OA, Bousquet J, Annesi-Maesano I: Assessing allergic rhinitis in developing countries. Int J Tuberc Lung Dis 14:506-712.

3. Zhang L, Han D, Huang D, Wu Y, Dong Z, Xu G, Kong W, Bachert C: Prevalence of self-reported allergic rhinitis in eleven major cities in china. Int Arch Allergy Immunol 2009, 149:47-57.

4. Wang HY, Zheng JP, Zhong NS: Time trends in the prevalence of asthma and allergic diseases over 7 years among adolescents in Guangzhou city. Zhonghua Yi Xue Za Zhi (Chin) 2006, 86:1014-1020

5. Platts-Mills TA, Wheatley LM, Aalberse RC: Indoor versus outdoor allergens in allergic respiratory disease. Curr Opin Immunol 1998, 10:634-9.

6. Bousquet J, Khaltaev N, Cruz AA, Denburg J, Fokkens WJ, Togias A, Zuberbier T, Baena-Cagnani CE, Canonica GW, van Weel C, Agache I, AïtKhaled N, Bachert C, Blaiss MS, Bonini S, Boulet LP, Bousquet $P$ J Camargos P, Carlsen KH, Chen Y, Custovic A, Dahl R, Demoly P, Douagui H, Durham SR, van Wijk RG, Kalayci O, Kaliner MA, Kim YY, Kowalski ML, Kuna P, Le LT, Lemiere C, Li J, Lockey RF, Mavale-Manuel S, Meltzer EO, Mohammad Y, Mullol J, Naclerio R, O'Hehir RE, Ohta K, Ouedraogo S, Palkonen S, Papadopoulos N, Passalacqua G, Pawankar R, Popov TA, Rabe KF, Rosado-Pinto J, Scadding GK, Simons FE, Toskala E, Valovirta E, van Cauwenberge P, Wang DY, Wickman M, Yawn BP, Yorgancioglu A, Yusuf OM, Zar H, Annesi-Maesano I, Bateman ED, Ben Kheder A, Boakye DA, Bouchard J, Burney P, Busse WW, Chan-Yeung M, Chavannes NH, Chuchalin A, Dolen WK, Emuzyte R, Grouse L, Humbert M, Jackson C, Johnston SL, Keith PK, Kemp JP, Klossek JM, Larenas-Linnemann D, Lipworth B, Malo JL, Marshall GD, Naspitz C, Nekam K, Niggemann B, Nizankowska-Mogilnicka E, Okamoto Y, Orru MP, Potter P, Price D, Stoloff SW, Vandenplas O, Viegi G, Williams D: World Health Organization; GA(2)LEN; AllerGen. Allergic Rhinitis and its Impact on Asthma (ARIA) 2008 update (in collaboration with the World Health Organization, GA(2) LEN and AllerGen). Allergy 2008, 63(Suppl 86):8-160.

7. Gruchalla RS, Pongracic J, Plaut M, Evans R, Visness CM, Walter M, Crain EF, Kattan M, Morgan WJ, Steinbach S, Stout J, Malindzak G, Smartt E, Mitchell H: Inner City Asthma Study: relationships among sensitivity, allergen exposure, and asthma morbidity. J Allergy Clin Immunol 2005, 115:478-485

8. Phipatanakul W, Celedon JC, Hoffman EB, Abdulkerim H, Ryan LM, Gold DR: Mouse allergen exposure, wheeze and atopy in the first seven years of life. Allergy 2008, 63:1512-1518.

9. Tovey ER, Almqvist C, Li Q, Crisafulli D, Marks GB: Nonlinear relationship of mite allergen exposure to mite sensitization and asthma in a birth cohort. J Allergy Clin Immunol 2008, 122:114-8, 8 e1-e5.

10. Calabria CW, Dice J: Aeroallergen sensitization rates in military children with rhinitis symptoms. Ann Allergy Asthma Immunol 2007, 99:161-169.

11. Rolinck-Werninghaus C, Keil T, Kopp M, Zielen S, Schauer U, von Berg A, Wahn U, Hamelmann E, Omalizumab Rhinitis Study Group: Omalizumab Rhinitis Study Group: Specific IgE serum concentration is associated with symptom severity in children with seasonal allergic rhinitis. Allergy 2008, 63:1339-1344.

12. Li J, Sun B, Huang $Y$, Lin $X$, Zhao D, Tan G, Wu J, Zhao H, Cao L, Zhong N, China Alliance of Research on Respiratory Allergic Disease: A multicentre study assessing the prevalence of sensitizations in patients with asthma and/or rhinitis in China. Allergy 2009, 64:1083-1092.

13. Sarpong SB, Karrison T: Skin test reactivity to indoor allergens as a marker of asthma severity in children with asthma. Ann Allergy Asthma Immunol 1998, 80:303-308.

14. Borish L, Chipps B, Deniz Y, Gujrathi S, Zheng B, Dolan CM, TENOR Study Group: Total serum lgE levels in a large cohort of patients with severe or difficult-to-treat asthma. Ann Allergy Asthma Immunol 2005, 95:247-253.

15. Siroux V, Oryszczyn MP, Paty E, Kauffmann F, Pison C, Vervloet D, Pin I: Relationships of allergic sensitization, total immunoglobulin $E$ and blood eosinophils to asthma severity in children of the EGEA Study. Clin Exp Allergy 2003, 33:746-751.

16. Siroux V, Kauffmann F, Pison C, Pin I: Multidimensional character of asthma severity in the EGEA study. Rev Mal Respir 2004, 21:917-924.

17. Bousquet J, Van Cauwenberge $P$, Khaltaev N: Allergic rhinitis and its impact on asthma. J Allergy Clin Immunol 2001, 108:S147-334.
18. GINA EXECUTIVE AND SCIENCE COMMITTEE: Global Strategy for Asthma Management and Prevention. 2006 [http://www.ginasthma.com/ Guidelineitem], Accessed 8th May 2007.

19. Petersen $A B$, Gudmann $P$, Milvang-Gronager $P$, Mørkeberg R, Bøgestrand $S$, Linneberg A, Johansen N: Performance evaluation of a specific lgE assay developed for the ADVIA centaur immunoassay system. Clin Biochem 2004, 37:882-892.

20. Bauchau V, Durham SR: Epidemiological characterization of the intermittent and persistent types of allergic rhinitis. Allergy 2005, 60:350-353.

21. Custovic ACM, editor: Indoor allergens as a risk factor for asthma. Philadelphia: Loppincott-Raven; 1997.

22. Lemanske RF Jr, Busse WW: 6. Asthma. J Allergy Clin Immunol 2003, 111: S502-519.

23. Al-Mousawi MS, Lovel H, Behbehani N, Arifhodzic N, Woodcock A, Custovic A: Asthma and sensitization in a community with low indoor allergen levels and low pet-keeping frequency. J Allergy Clin Immunol 2004, 114:1389-1394.

24. Platts-Mills TA, Thomas WR, Aalberse RC, Vervloet D, Champman MD: Dust mite allergens and asthma: report of a second international workshop. J Allergy Clin Immunol 1992, 89:1046-1060.

25. Huss K, Adkinson NF Jr, Eggleston PA, Dawson C, Van Natta ML, Hamilton RG: House dust mite and cockroach exposure are strong risk factors for positive allergy skin test responses in the Childhood Asthma Management Program. J Allergy Clin Immunol 2001, 107:48-54.

26. He J LC: Survey of house dust mites in indoor environment in Huainan area. J Environ Health (Chin) 2005, 22:270.

27. Li JL, Xing ZM, Wang ZH, Zhang P, Li AQ, Liu JZ: Investigation on indoor air biological pollution of house in patients with perennial allergic rhinitis. J Environ Health (Chin) 2005, 22:269-270.

28. Zhang C, Gjesing B, Lai X, Li J, Spangfort MD, Zhong N: Indoor allergen levels in Guangzhou city, southern China. Allergy 2011, 66:186-91.

29. Lichtenstein LM, Ishizaka K, Norman PS, Sobotka AK, Hill BM: IgE antibody measurements in ragweed hay fever. Relationship to clinical severity and the results of immunotherapy. J Clin Invest 1973, 52:472-482.

30. Norman PS, Lichtenstein LM, Ishizaka K: Diagnostic tests in ragweed hay fever. A comparison of direct skin tests, IgE antibody measurements, and basophil histamine release. J Allergy Clin Immunol 1973, 52:210-224.

31. Nickelsen JA, Georgitis JW, Reisman RE: Lack of correlation between titers of serum allergen-specific IgE and symptoms in untreated patients with seasonal allergic rhinitis. J Allergy Clin Immunol 1986, 77:43-48.

32. Somville MA, Machiels J, Gilles JG, Saint-Remy JM: Seasonal variation in specific lgE antibodies of grass-pollen hypersensitive patients depends on the steady state $\operatorname{lgE}$ concentration and is not related to clinical symptoms. J Allergy Clin Immunol 1989, 83:486-494.

33. Niggemann B, Rolinck-Werninghaus C, Mehl A, Binder C, Ziegert M, Beyer K: Controlled oral food challenges in children-when indicated, when superfluous? Allergy 2005, 60:865-870.

34. Wan H, Winton HL, Soeller C, Gruenert DC, Thompson PJ, Cannell MB, Stewart GA, Garrod DR, Robinson C: Quantitative structural and biochemical analyses of tight junction dynamics following exposure of epithelial cells to house dust mite allergen Der p 1. Clin Exp Allergy 2000, 30:685-698.

35. Baker SF, Yin Y, Runswick SK, Stewart GA, Thompson PJ, Garrod DR, Robinson C: Peptidase allergen Der $p 1$ initiates apoptosis of epithelial cells independently of tight junction proteolysis. Mol Membr Biol 2003, 20:71-81.

36. Simpson BM, Custovic A, Simpson A, Hallam CL, Walsh D, Marolia $\mathrm{H}$, Campbell J, Woodcock A: NAC Manchester Asthma and Allergy Study (NACMAAS): risk factors for asthma and allergic disorders in adults. Clin Exp Allergy 2001, 31:391-399.

doi:10.1186/1465-9921-12-95

Cite this article as: Li et al:: Influence of degree of specific allergic sensitivity on severity of rhinitis and asthma in Chinese allergic patients. Respiratory Research 2011 12:95. 